\title{
Development of women in senior leadership roles in Saudi Arabia
}

\author{
Azhar Gawarir \\ University of Brighton / Brighton business school
}

\begin{abstract}
.
Arabs in general and Saudis in particular have a very traditional view of the role of gender in society. Previously, leadership in the western context was characterized by men taking over leadership positions when leading from the front. However, currently, there have been significant steps taken by various movements to preach gender equality leading to the rise in women in leadership positions. However, things are slightly different as women are given opportunities to engage in critical decision making in society. In Arab nations, there are more women occupying government positions than other regions in the world. In Saudi Arabia, things are different as organizations continually look for potential individuals who can learn from experiences and take leadership positions. On the issue of women, they receive obstacles in getting knowledge that will enable them to acquire leadership positions.
\end{abstract}

Keywords: women, gender, leadership, Saudi Arabia, empowerment. 